Bulletin of Pharmaceutical Sciences
Assiut University

\title{
MICROORGANISMS ASSOCIATED WITH DIABETIC FOOT ULCERS
}

Khaled Mohammed Hassanin ${ }^{1}$, Entsar Hamed Ahmed ${ }^{1}$, Mohammed Ahmed Al-Mokhtar ${ }^{1}$ and Hend Mamdoh Youssef ${ }^{2 *}$

${ }^{1}$ Department of Medical Microbiology and Immunology, Faculty of Medicine, Assiut University, Assiut, Egypt

${ }^{2}$ Al-Rajhy Liver Hospital, Assiut University, Assiut, Egypt

Background: Non-traumatic lower limb amputation is the most common devastating complication of diabetes, primarily due to diabetic foot ulcers (DFU) and diabetic foot infections (DFI). DFIs are predominantly polymicrobial and multidrug-resistant (MDR) and results in treatment failure.

Aims: The main objectives of the study are to identify the microorganisms associated with diabetic foot ulers.

Methods: This was a prospective study at a tertiary care hospital. One hundred patients over the age of 18, having chronic diabetic foot ulcer, and attending the diabetic foot outpatient department were included. Samples of pus were collected from deep wounds and processed using standard techniques for culture

Results: One hundred samples were processed and 82 yielded positive cultures. Staphylococcus aureus was the predominant organism, followed by Pseudomonas aeruginosa. Then E coli, Klebsiella and Proteus

Conclusion: The organisms causing chronic diabetic foot ulcers were commonly Staphylococcus aureus followed by Pseudomonas aeruginosa.

\section{INTRODUCTION}

Diabetes mellitus is a chronic condition due to disturbance in carbohydrate, protein and fat metabolism that occurs when there are raised levels of glucose in the blood because the body cannot produce any or enough of insulin or use insulin effectively. Insulin is an essential hormone produced in the pancreas, and it transports glucose from the bloodstream into the body's cells where the glucose is converted into energy. The lack of insulin or the inability of the cells to respond to insulin leads to high levels of blood glucose, or hyperglycaemia, which is the hallmark of diabetes. Hyperglycaemia, if left unchecked over the long term, can cause damage to various body organs, leading to the development of disabling and life-threatening health complications such as cardiovascular disease, neuropathy, nephropathy and eye disease, leading to retinopathy and blindness. On the other hand, if appropriate management of diabetes is achieved, these serious complications can be delayed or prevented ${ }^{1}$.

\section{Diabetes complications}

Diabetes complications can be divided into acute and chronic complications. Acute complications include hypoglycaemia, diabetic ketoacidosis, hyperglycaemic hyperosmolar state, hyperglycaemic diabetic coma, seizures or loss of consciousness and infections. Chronic microvascular complications are nephropathy, neuropathy and retinopathy, whereas chronic macrovascular complications are coronary artery disease leading to angina or myocardial infarction, peripheral artery disease (PAD) contributing to stroke, diabetic encephalopathy and diabetic foot ${ }^{1}$. In addition, diabetes has also been associated with increased rates of cancer $^{2}$, physical and

Received in 26/2/2019 \& Accepted in 6/11/2019 
cognitive disability ${ }^{3 \& 4}$, tuberculosis ${ }^{5 \& 6}$ and depression ${ }^{7}$.

With the lifetime, incidence of foot ulcers occurring in up to $25 \%$ of patients. Diabetes morbidity rates are staggeringly high and the 5year mortality rate, after a lower extremity amputation, is only second to lung cancer".

The prevalence of active foot ulceration varies from approximately $1 \%$ in certain European and North American studies to more than $11 \%$ in reports from some African countries $^{9}$. In developing countries, foot ulcers and amputations are unfortunately very common. Poverty, a lack of sanitation and hygiene, and barefoot walking often interact to compound the impact of diabetic foot damage. In low income countries, the lack of access to adequatehealth care, together with economic and geographical factors, often prevent people with diabetes from seeking medical treatment for foot lesions until these have become severely infected ${ }^{10}$.

Sole or predominant bacterial species identified on culture of a good quality specimen (and seen, where available, on Gram-stained smear) are likely true pathogens. In most centres, Staphylococcus aureus(S. aureus) is the most frequently isolated, and perhaps most virulent, pathogen, whether alone or in combination. Streptococci (various groups of $\beta$-haemolytic and others) are also important pathogens. Enterococci are relatively frequent isolates but usually of secondary clinical importance $^{11}$.

Infections requiring hospitalization are often polymicrobial and may include various types of aerobes and anaerobes ${ }^{12 \& 13}$.

Gram-negative bacilli (mainly Enterobacteriaceae, sometimes Pseudomonas aeruginosa ( $P$. aeruginosa), or other Gramnegative species) are usually isolated in conjunction with Gram-positive cocci from patients with chronic or previously treated infections ${ }^{11}$.

Many recent studies have reported that Gram-negative organisms (especially $P$. aeruginosa)are the most frequent isolates in DFIs occurring in patients in warm climates, especially in Asia and Africa ${ }^{14 \& 15}$. It is unclear if this is related to environmental factors, footwear, personal hygiene, antimicrobial.

Pretreatment or other factors. Obligate anaerobic species are most frequently isolated from ischaemic or necrotic wounds or those that involve deep tissues; they are rarely the sole pathogen and most often are part of a mixed infection with aerobes ${ }^{16}$.

\section{PATIENTS AND METHODS}

This study was conducted in department of medical microbiology and immunology, faculty of medicine, Assuit university hospitals during the period from September 2017 to September 2018.

\section{Patients}

Patients who admitted to diabetic foot outpatient clinic in the diabetes and endocrinology centre and vascular surgery outpatient clinic in Assuit University Hospital.

\section{Inclusion criteria}

All patients had diabetic foot ulcers. The overt clinical signs associated with local wound infections are:

- Discharge of pus.

- Swelling, pain, erythema and local warmth

- evidence of surrounding tissue involvement or wound breakdown; wound appears infected or deteriorating and probing infection to the bone (cellulitis, osteomyelitis or gangrene).

\section{Exclusion criteria}

- Non-diabetic patient.

- Healed wounds.

\section{Data collection}

The following variables were recorded:

1- Patients demographic data.

2- Smoking status.

3- Family history of diabetes.

4- Duration of diabetes.

5- Co-morbid diseases and complications of diabetes.

6- Haemoglobin A1C.

7- Treatment of diabetes.

8- ABI (Ankle Brachial Index).

9- Type of ulcer.

10- Ulcer characteristics (position depth, edge, base, infection grade).

\section{Ethical consideration}

Informed consent was obtained from all cases. Ethical approval was taken from the 
scientific ethics committee of faculty of Medicine, Assuit University

\section{Methods of the study \\ Specimen collection and processing}

Swab was taken from diabetic foot ulcers by sterile disposable cotton swabs, then adding $5 \mathrm{ml}$ of sterile Brain Heart Infusion Broth (BHI) and transferred to the laboratory of Medical Microbiology and Immunology department, faculty of Medicine, Assuit University

\section{I- Microscopic examination}

By simple light microscopy with oil immersion lens using Gram stain.

Microscopic identification: $S$. aureus appears as gram positive cocci arranged in grape like clusters.

\section{II- Cultures}

Swabs were incubated at $37^{\circ} \mathrm{C}$ for 24 hours then they were incubated aerobically using the following media:

A- Nutrient agar medium (NA) (Oxoid, England).

Preparation: (according to manufacturer's instructions).

B- Blood agar medium.

Preparation: The blood agar medium was made by adding aseptically $50 \mathrm{ml}$ of fresh human blood to $950 \mathrm{ml}$ of nutrient agar (Oxoid England). Nutrient agar was sterilized by autoclaving and allowed to cool to $50^{\circ} \mathrm{C}$. Human blood was added aseptically. The agar was mixed and distributed into plates.

The primary culturing was done by directly streaking on blood agar plate and incubated at $37^{\circ} \mathrm{C}$ for 24 hours under aerobic conditions.

C- Mannitol Salt agar (MSA) (Oxoid, England) Preparation: (according to manufacturer's instructions).

D- Macconkey agar (Oxoid, England).

Preparation: (according to manufacturer's instructions).

\section{III- Biochemical reactions}

Oxidase strip test for detection $P$. auerogenosa.

\section{Biochemical reactions}

A- Catalase test

Catalase test was performed as recommended by ${ }^{17 \& 18}$. As follows; a colony (18-24 hrs) was transferred to a center of glass slide using a sterile glass rod. then 1 drop of $3 \%$ hydrogen peroxide was added.

The rapid and sustained effervescence within $3 \mathrm{o} \mathrm{sec}$. constitutes a positive test.

\section{B- Coagulase test}

coagulase test is used to differentiate $S$. aureus (positive) which produce the enzyme coagulase, from $S$. epidermidis and S.saprophyticus (negative) which do not produce coagulase. i.e. Coagulase Negative Staphylococcus (CONS)

\section{Principle of the test}

Coagulase is an enzyme-like protein and causes plasma to clot by converting fibrinogen to fibrin. $S$. aureus produces two forms of coagulase: bound and free.

Bound coagulase (clumping factor) is bound to the bacterial cell wall and reacts directly to the fibrinogen. This results in an alteration of fibrinogen so that it precipitates on the Staphylococcal cell, causing the cells to clump when a bacterial suspension is mixed with plasma. This doesn't require coagulase reacting factor ${ }^{19}$.

Free coagulase involves the activation of plasma coagulase reacting factor (CRP), which is a modified or derived thrombin molecule, to form a coagulase-CRP complex. This complex in turn reacts with fibrinogen to produce fibrin $\operatorname{clot}^{19}$.

\section{Procedure and types of coagulase test}

Slide test (to detect bound coagulase) ${ }^{19}$

1- A drop of physiological saline was placed on each end of a slide, or on two separate slides.

2- With the loop, straight wire or wooden stick, a portion of the isolated colony was emulsified in each drop to make two thick suspensions.

3- A drop of human plasma was added to one of the suspensions, and mixed gently.

4- Clumping of the organism was noticed within 10 seconds.

5- No plasma is added to the second suspension as a negative control. 


\section{Interpretations}

- Fibrin clot of any size: positive.

- No clot: negative.

- Clumping in both drops of slides indicates that the organism auto agglutinates and is unsuitable for the slide coagulase test.

- The entire negative slide test must be confirmed using the tube test.

- During slide test there may be chance to false positive results in case of citrate utilizing bacteria (Enterococcus and Pseudomonas). In this case also, tube test should be performed and confirmed ${ }^{17}$. Tube test (to detect free coagulase) ${ }^{19}$.

The plasma was diluted 1 in 10 in physiological saline $(0.2 \mathrm{ml}$ of plasma was mixed with $1.8 \mathrm{ml}$ of saline).

1- small test tubes (3) were labelled as $\mathrm{T}$ (test), $\mathrm{P}$ (positive control) and $\mathrm{N}$ (negative control). Test is $18-24 \mathrm{hrs}$ broth culture; positive control is $18-24 \mathrm{hrs} S$. aureus (coagulase positive) broth culture and negative control is sterile broth.

2- Diluted plasma $(0.5 \mathrm{ml})$ was pipetted into each tube.

3- 5 drops $(0.1 \mathrm{ml})$ of the test organism were added to tube labelled "T", 5 drops of $S$. aureus culture to the tube labelled "P" and 5 drops of sterile broth to the tube labelled "N".

4- After mixing, the three tubes were incubated at $35-37^{\circ} \mathrm{C}$.

5- Clotting was examined after 1 hour. If no clotting had occurred, it was examined at 30 minutes intervals up to $6 \mathrm{hrs}$.

\section{Interpretation}

- Medium is solid: plasma has been clotted.

- Medium is liquid: plasma has not been clotted.

\section{RESULTS AND DISCUSSION}

\section{Patient characteristics}

The mean age \pm SD was $54.75 \pm 12.11$. The range was (22-78). The sex distribution among the studied population was 58 males representing (58\%) of all patients and 42 females representing (42\%) of all patients. According to the patients BMI $38 \%$ were obese (BMI> 30), 26\% were overweight (BMI 25-30) and $36 \%$ were normal weight (BMI 18.5-25).
Regarding to smoking status $22 \%$ were current smokers, $23 \%$ were ex-smokers and $55 \%$ were non-smokers. About presence of family history of diabetes from $1^{\text {st }}$ degree relatives it was shown that $66 \%$ of all patients had family history of diabetes and $34 \%$ were negative family history for diabetes.

Duration of diabetes was ranging from 135 years.Hemoglobin A1C (HbA1c) was controlled $(<7 \%)$ in 12 patients while 88 patients had uncontrolled HbA1c (>7\%), 17 cases had HbA1c (7\%-9\%) and 71 patients had their $\mathrm{HbA} 1 \mathrm{c}>9 \%$. $63 \%$ of all patients were treated by insulin only, $24 \%$ were on oral hypoglycemic agents and 13\% were on both oral hypoglycemic agents and insulin.

Regarding to complications of diabetes and other chronic diseases 37 patients were hypertensive, 10 patients had nephropathic disease, 33 had retinopathy, 55 had neuropathy, 13 had cardiovascular disorders and 13 had cerebrovascular diseases and 24 had peripheral vascular disease.

Ulcers were varied between ischemic, neuropathic or mixed type as shown in figure 1. 5-Gram negative bacteria (Fig. 2): Gram negative varied between, Pseudomonas SPP (42), Klebsiella SPP (30), Ecoli (33) and Proteus (13).

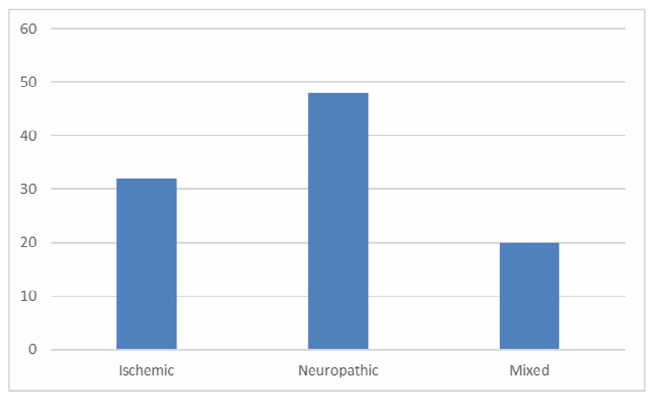

Fig. 1: Types of ulcers.

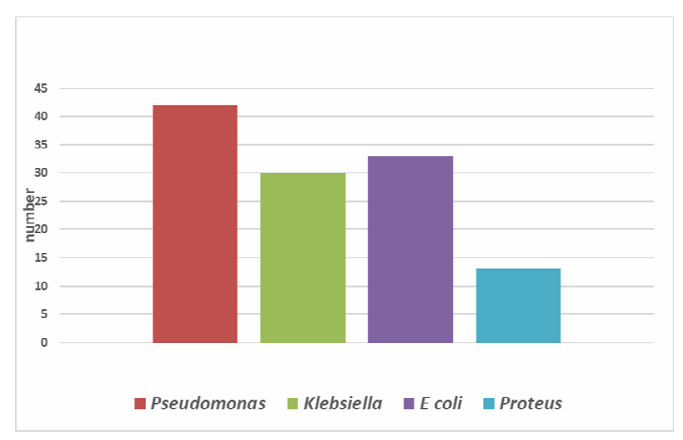


Fig. 2: Types of isolated Gram-negative bacteria. Discussion

As diabetes is increasing especially in developing countries, the problem of diabetic foot infection with a potential risk for amputation is rapidly growing, with challenges in diagnosis and treatment ${ }^{1}$.

Chronically infected diabetic foot ulcer, often associated with polymicrobial biofilm formation, is considered the most significant wound care problem in the world affecting up to $25 \%$ of diabetic individuals at least once in their lifetime ${ }^{20}$.

S.aureus poses a great risk to patients with wounds; significant increase in both mortality and morbidity has been reported in patients infected with S.aureus due to development of biofilms. S.aureus is frequently resistant to a wide variety of antibiotics, and this is more pronounced in those having ability to form biofilm $^{21}$. In this study the mean age of the studied population was $54.75 \pm 12.11$, The range was (22-78).

In our study males were more than females $(58 \%)$ of all patients in our study. This is consistent with $^{21 \& 22}$. In another studies $^{23}$ females with $S$. aureus infected ulcers were more than males $(57 \%)$ and $(52 \%)$ respectively which is inconsistent with this study's demographics.

Such difference in prevalence of S.aureus and in demographics could be due to difference of patient groups,hospitals, time periods and geographical locations

Among 64 isolated S. aureus strains, 56 $(87.5 \%)$ were detected as MRSA phenotypically and $81 \%$ were posirive to mecA gene this percentage agreed with $^{24}$. The high incidence of MRSA in our hospital may be due to many risk factors like:Being hospitalized: MRSA remains a concern in hospitals, where it can attack those most vulnerable - older adults and people with weakened immune systems,Having an invasive medical device: Medical tubing - such as intravenous lines or urinary catheters - can provide a pathway for MRSA to travel into your body and the misuse of penicillin group drugs over the last decades.

\section{REFERENCES}

1- IDF DIABETES ATLAS, $8^{\text {th }}$ Ed. (2017).
2- W. Fendler, B. M., A. BaranowskaJazwiecka, et al., "Prevalence of monogenic diabetes amongst Polish children after a nationwide genetic screening campaign", Diabetologia, 55, 2631-35 (2012). DOI: http://dx.doi. org/10.1007/s00125-012-2621-2.

3- J. Kropff, S. M., M. I. McCarthy, et al., "Prevalence of monogenic diabetes in young adults: A community-based, crosssectional study in Oxfordshire, UK", ibid., 54, 1261-63 (2011). DOI: http://dx.doi.org/10.1007/s001250112090-z.

4- E. R. Thomas, B. A., J. Kidd, et al., "Diagnosis of monogenic diabetes: 10Year experience in a large multi-ethnic diabetes center", J. Diabetes Investig., 7, 332-37 (2016). DOI: http://dx.doi.org/ 10.1111/jdi.12432.

5- R. G. Gandica, C. W., L. Deng, et al., "Identifying monogenic diabetes in a pediatric cohort with presumed type 1 diabetes: Identifying pediatric monogenic diabetes", Pediatr. Diabetes, 16, 227-33 (2015). DOI: http://dx.doi.org/10.1111/ pedi.12150.

6- R. Murphy, E. S. and A. T. Hattersley, "Clinical implications of a molecular genetic classification of monogenic betacell diabetes", Nat. Clin. Pract. Endocrinol. Metab., 4, 200-13 (2008). DOI: http://dx.doi.org/10.1038/ ncpendmet0778.

7- A. S. and S., "Monogenic diabetes in children and young adults: Challenges for researcher, clinician and patient", Rev. Endocr. Metab. Disord., 7, 171-85 (2006).

DOI: http://dx.doi.org/10.1007/s1 1154-0069014-0.

8- Organization, W. H., World Health Organization, "Definition and Diagnosis of Diabetes Mellitus and Intermediate Hyperglycemia: Report of a WHO/ IDF Consultation", World Health Organization (2006).

9- A. J. Boulton, V. L., G. RagnarsonTennvall and J. Apelqvist, "The global burden of diabetic foot disease", The Lancet., 366 (9498), 1719-24 (2005).

10- A. J. M. Boulton, D. G. Armstrong, S. F. Albert, et al., "Comprehensive foot 
examination and risk assessment", Diabetes Care, 31, 1679-85 (2008). DOI: http://dx.doi. org/10.2337/dc08-9021.

11- P. W. Moxey, G. P., R. J. Hinchliffe, et al., "Lower extremity amputations - A review of global variability in incidence", Diabetic Medicine, 28 (10), 1144-53 (2011). DOI: http://dx.doi.org/10.1111/ j.14645491.2011.03279.x.

12- R. Hasan, F. B., T. Elraiyah, et al., "A systematic review and meta-analysis of glycemic control for the prevention of diabetic foot syndrome", J. Vasc. Surg., 63, 22S-8S (2016). DOI: http://dx.doi. org/10.1016/j.jvs.2015.10.005.

13- N. C. and S., "Diabetic foot ulcer classification system for research purposes: A progress report on criteria for including patients in research studies", Diabetes Metab. Res. Rev., 20 Suppl 1, 90-95 (2004).

14- B. A. Lipsky, R. J. and J. P. Lavigne, "Diabetic foot ulcer microbiome: One small step for molecular microbiology... One giant leap for understanding diabetic foot ulcers?", Diabetes, 62, 679-681 (2013).

15- D. M. Citron, G. E., C. V. Merriam, B. A. Lipsky and M. A. Abramson, "Bacteriology of moderate-to-severe diabetic foot infections and in-vitro activity of antimicrobial agents", J. Clin. Microbiol., 45, 2819-2828 (2007).

16- R. Yoga, K. A., K. Sunita and C. Suresh, "Bacteriology of diabetic foot lesions", Med. J. Malaysia., 61 Suppl. A, 14-16 (2006).

17- S. Matsuzaki, R. M., J. Uchiyama, S. Sakurai, T. Ujihara, M. Kuroda, et al., "Bacteriophage therapy: A revitalized therapy against bacterial infectious diseases", J. Infect. Chemother., 11, 2119 (2005). PMID:16258815; DOI:10.1007/ s10156-005-0408-9.
18- E. W. Koneman, S. D. A., W. M. Janda, P. C. Schreckenberger and W .C. Winn Jr, "The Gram positive cocci.: Part II: Streptococci, Enterococci, and the "Streptococcus-like bacteria"", (1997).

19- E. W. Koneman, S. D. A., W. M. Janda, P. C. Schreckenberger and W. C. Winn Jr (Eds.), "Color Atlas and Textbook of Diagnostic Microbiology", $5^{\text {th }}$ Ed., J. B. Lippincott Co, Philadelphia, 1997, pp. 577-588.

20- Lina and G. E. A., "Bacterial competition for human nasal cavity colonization: Role of staphylococcal agr alleles", Appl. Environ. Microbiol., 69, 18-23 (2003).

21- D. Muluye, Y. W., G. Ferede, et al., "Bacterial isolates and their antibiotic susceptibility patterns among patients with pus and/or wound discharge at Gondar university hospital", BMC Research Notes, 7 (1), article 619 (2014).

22- D. Muluye, Y. W., G. Ferede, et al., "Bacterial isolates and their antibiotic susceptibility patterns among patients with pus and/or wound discharge at Gondar university hospital", ibid., 7 (1), article 619 (2014).

23- K. M. Pickwell, S. V., M. Kars, P. E. Holstein and N. C. Schaper, "Diabetic foot disease: Impact of ulcer location on ulcer healing", Diabetes Metab. Res. Rev., (2013).

24- P. J. Neetu and M. S., "Biofilm formation by methicillin resistant Staphylococcus aureus and their antibiotic susceptibility pattern: An in-vitro study", Curr. Res. Bacteriol., 7, 1-11 (2014). 


نشرة العلوم الصيدليـــة

الكائنات الاقيقة المصاحبة لقرح القدم السكري

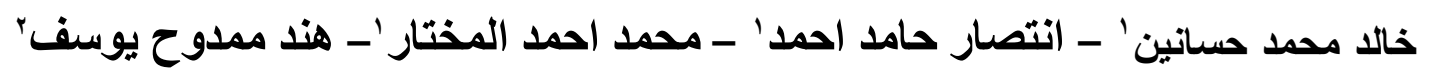

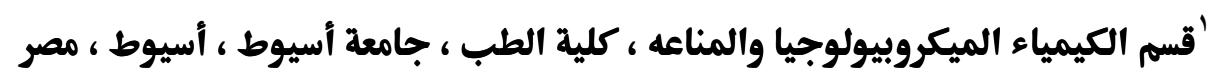

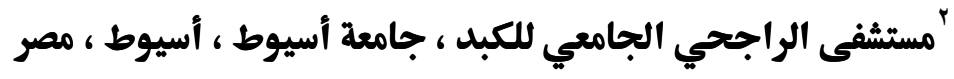

تعتبر قرحة القدم السكري من مضاعفات عدم انتظام مستوى السكر في الدم تصيب القدم وهي

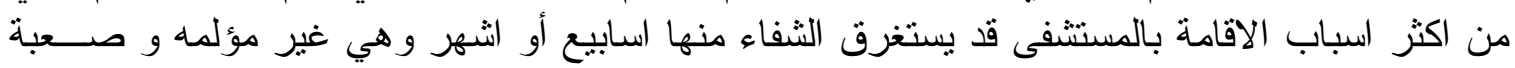

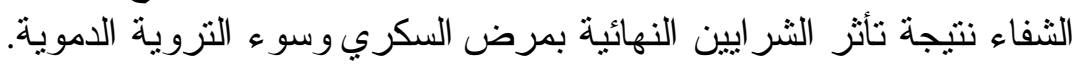

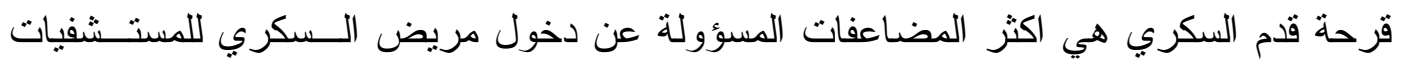
وعن اكثز عمليات البتر في الدول المنقدمة. قد تبدا عن طريق ضربة مبانشرة او جرح بسيط لا يشعر المريض به من البداية فنتطور الحالة لتصبح قرحة سكرية.

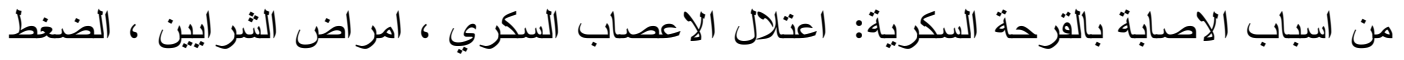
، تتوه القدم. ومن أكثر البكتريا المصاحبة لها هي: الدكورات العنقودية ، البكتريا الزائفة ، الكلبسيلة. 